\title{
Pandemic Analytics: How Countries are Leveraging Big Data Analytics and Artificial Intelligence to Fight COVID-19?
}

\author{
Nishita Mehta ${ }^{1}$ (D) $\cdot$ Sharvari Shukla ${ }^{2}$ D
}

Received: 7 July 2021 / Accepted: 4 October 2021 / Published online: 9 November 2021

(c) The Author(s), under exclusive licence to Springer Nature Singapore Pte Ltd 2021

\begin{abstract}
Emergence of coronavirus in December 2019 and its spread across the world in the following months has made it a global health concern. The uncertainty about its evolution, transmission and effect of SARS-CoV-2, has left the countries and their governments in a worrisome state. Ambiguity about the strategies that would work towards mitigating the impact of virus has prompted them to use data-driven methods. Several countries started applying big data and advanced analytics technology for management of the crisis. This study aims to understand how different nations have employed analytics to deal with COVID-19. This paper reviews various strategies employed by different governments and organizations across nations that use advanced analytics to tackle pandemic. In the current emergency of corona virus, there have been several measures that organizations have taken to mitigate its impact, thanks to the evolution of computing technology. Big data and analytical tools provide various solutions like detection of existing COVID-19 cases, prediction of future outbreak, anticipation of potential preventive and therapeutic agents, and assistance in informed decision-making. This review discusses the big data analytics and artificial intelligence approaches that policy makers, researchers, epidemiologists and private organizations have adopted. By examining the different ways and areas where data analytics has been utilized, this study provides the other nations with the progressive scheme to address the pandemic.
\end{abstract}

Keywords Pandemic analytics $\cdot$ Big data $\cdot$ Advanced analytics $\cdot$ Artificial intelligence $\cdot$ COVID-19 $\cdot$ Coronavirus

\section{Introduction}

The first 2 decades of twenty-first century have shown how infectious diseases are spreading globally-faster and more widely - mostly by way of increased intercontinental air travels. After SARS, H1N1, MERS, Ebola and Zika Virus, it is the Coronavirus disease 2019 (COVID-19) which is a global health threat today. Poor understanding of the incubation period and duration of infectious period for COVID-19 [1]; higher rate of its spread; and mortality 3,947,630 (at the

This article is part of the topical collection "Machine Learning for Pandemic Prediction and Control" guest edited by Anand J Kulkarni, Akash Tayal, Patrick Siarry, Arun Solanki and Ali Husseinzadeh Kashan.

Sharvari Shukla

director@ssi.edu.in

Symbiosis International (Deemed University), Pune, India

2 Symbiosis Statistical Institute, Symbiosis International (Deemed University), Pune, India time of writing of paper), heightens the concern even more. One way the epidemics of this scale can be managed is by a collaborative approach—be it academicians coming together for research on preventive or curative measures; or industries joining forces to provide adequate and timely resources; notfor-profit organizations coming to the rescue of vulnerable population; or even the governments ensuring proactive information dissemination, transparency of its actions and resource-sharing to better tackle the current situation.

Increased access to information, that is obtained either through streams of real-time spatial data depicting travel patterns of individuals or through cooperative governmental efforts or maybe the partnership activities of research communities, provide varied opportunities to address the current crisis. Vast amounts of data so generated, termed as big data, are the rich source of information for monitoring the spread of disease. Identification of patterns through analysis of these data streams can help to comprehend shifts in disease hotspots and support surveillance actions. Scaling the use of analytical tools on such large volumes of data, for examining the proliferation of disease and understanding 
the global state of pandemic can be referred to as Pandemic analytics [2].

There are a bunch of unknowns with COVID-19-how does the virus strain differ from previous known strains, what is the virus' behavior and its ability to infect, what is the disease incubation period, what are the true number of infections, whether the patients once infected and recovered will be protected against a repeat infection, how long does the virus live in the environment, can surface contact lead to transmission and many more [3]. Amidst this ambiguity, the centralization of all relevant data, be it unstructured or disorganized, and its analysis provides certain ability to derive insights on the transmission of disease. Hopeful about its potential, worldwide different nations and organizations are looking forward to using big data analytics and artificial intelligence (AI) for better management of the crisis. This study reviews the early steps of governments and private firms in using these digital technologies to slow down the spread of the disease. Figure 1 depicts the map of COVID19-confirmed cases reported to WHO and highlights the early adopters of AI and other cognitive tools as identified through review.

\section{Applications of Big Data Analytics and AI in COVID-19}

\section{First Warnings by Canada-Based Company}

Days before the World Health Organization (WHO) released its statement on COVID-19, BlueDot, a Toronto-based infectious disease surveillance company, had alerted its clients of a cluster of unusual pneumonia cases in Wuhan. With the expertise in infectious diseases, big data analytics and digital technologies, this company found patterns across news reports that indicated the possible outbreak of infectious disease [4].

\section{China Tracks COVID-19 with the Use of Big Data Analytics}

Initial efforts by technology firms in China were in utilizing movement data to track the flow of population and understand the spread of disease. Telecom firm, Unicom, primarily provided reports on the public flow across 31 provincial traffic and health departments [5]. On the other hand, GeTui, a smart data provider, created a heat map of the outbreak in China by monitoring the movement of passengers from the worst-hit city of Wuhan [5]. Following that, a big data analytics platform which pooled data from National Health Commission, Ministry of Transport, China Railway and Civil Aviation Administration of China, was launched to help authorities identify the close contacts of COVID-19

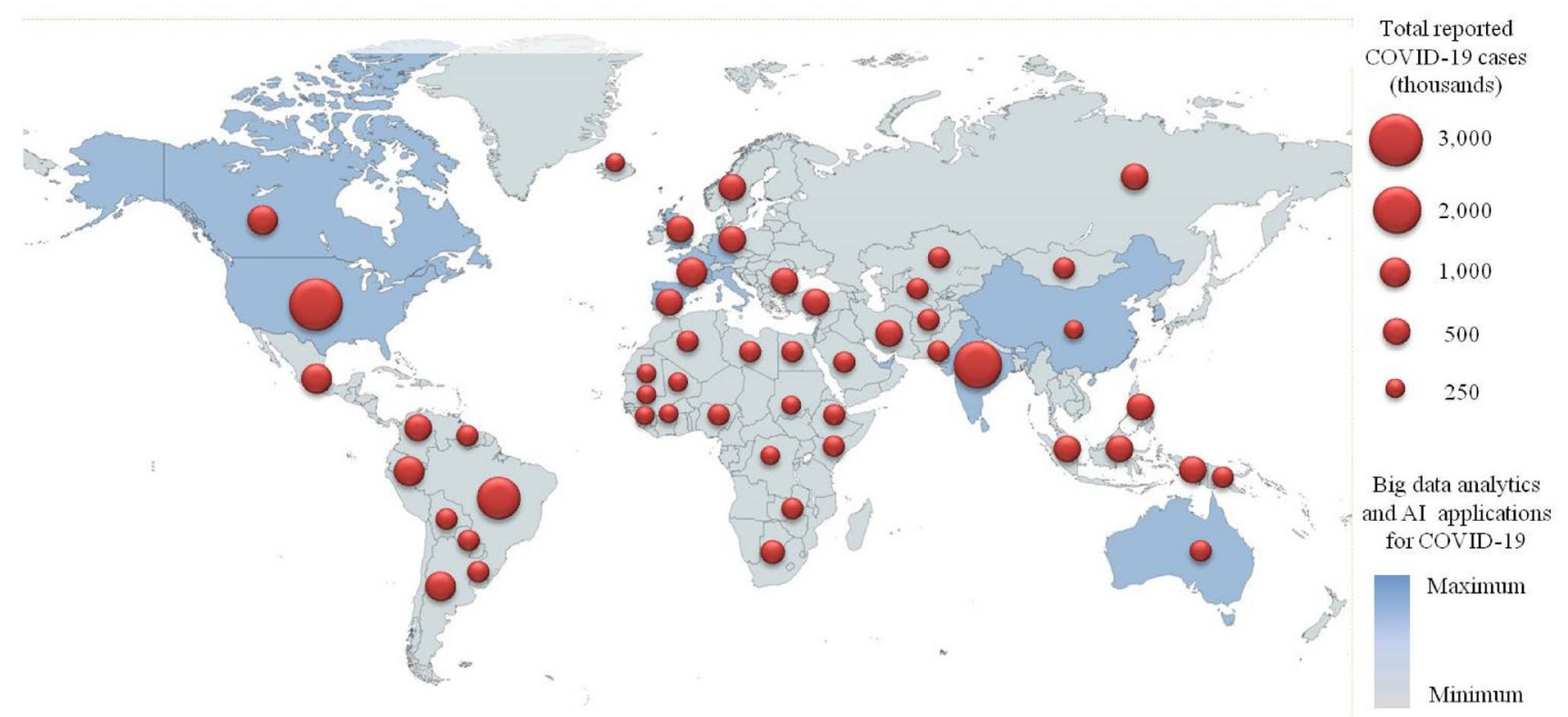

Fig. 1 Application of big data analytics and AI; and total reported COVID-19 cases by countries [8] 
patients or suspects [6]. Baidu, another technology company, created a map to provide real-time updates on the information of road closure and crowded areas to guide people in avoiding such places [7].

The Chinese government in collaboration with Alipay, a private online payment platform, has also created a smartphone app which gives color codes to the citizens based on the contagion risk, to help authorities track the people's movement [9]. Moreover, the government is also using big data analytics in decision-making-for instance, Beijing municipal government used analytics to evaluate the merits and demerits and made a decision on suspending inter-provincial road transport while not restricting the civil aviation and high-speed railways [7].

On the healthcare front, railway stations and subways in China have deployed AI-based temperature scanners by Megvii Technology, that use body and facial detection to identify people with elevated body temperatures [10]. Chinese multinational company Alibaba is providing a CT Image Analytics Solution to the clinicians involved in COVID-19 disease management for faster and accurate testing [11]. A similar system was developed by Nankai University and Inference Technology, which assists physicians in diagnosis by rapidly screening and analyzing large number of high-resolution CAT scans [12].

\section{Early Intervention by Taiwan}

As soon as the word of outbreak of unknown pneumonia in China was out in the world, Taiwan had an immediate response to the upcoming crisis. Owing to its proximity and frequent travel to China, the state had been at the highest risk. Despite that, with its lessons from 2003 SARS outbreak, Taiwan adopted technology-driven strategies for prompt action. By centralizing the data with integration of the national health insurance database and immigration and customs database, the government was able to create a detailed map of 14-day travel histories and symptoms of its citizens and travelers [13]. The use of big data analytics on this pooled data enabled real-time alerts for hospitals and clinics assisting them in diagnoses and treatment and also allowed early identification of potential cases [14].

Moreover, the combination of big data analysis and mobile-phone location tracking in the form of "electronic fence" provided Taiwanese government an opportunity to ensure quarantine compliance [15]. Predictive analytics was also used to provide real-time updates on highrisk zones alerting public to avoid those locations [14]. Besides, data-driven insights helped track the availability of critical medical supplies. The government followed up on an interactive real-time map of the stock of supplies created by one of the software engineers. The locals could use this online map to obtain the information about availability of masks, including details of pharmacies providing them and their distance from the seeker [16].

\section{NHS England Allocates ‘Big Data Platform' to Defeat Coronavirus}

With the purpose of providing up-to-date information to the decision-makers, UK's National Health Service (NHS) partnered with Microsoft, Amazon Web Services, Google, Faculty and Palantir to build a digital platform based on big data, AI and cloud computing technology [17]. The platform sourced COVID-19-related data from NHS and Public Health England, analyzed it and presented the authorities with real-time insights and recommendations in the form of a dashboard [18]. ZOE, a UK-based health science company, in collaboration with researchers from King's College London and Massachusetts General Hospital Boston, designed an AI model to predict COVID-19 infections [19]. Based on the data obtained from ZOE's "COVID Symptom Study app", the outcomes of this model aid public when access to traditional testing is limited. In collaboration with researchers from University of Cambridge, COVID-19 Capacity Planning and System (CPAS) was launched by NHS, to anticipate the need for hospital resources like equipments including ICU beds and ventilators in coronavirus patient management [20].

BenevolentAI, a London-based firm, utilized its drug discovery platform to spot drugs which had the potential to treat COVID-19 patients, driving its clinical trials [21]. Oxford-based Exscientia formed an alliance with Diamond Light Source and Scripps Research's Calibr to use AI and screen 15,000 drugs in search for a potent existing anti-viral drug that could be repurposed for treatment of COVID-19 [22]. Pharmacology-AI firm based in Cambridge, AI VIVO, with the help of its predictive engine identified Dexamethasone as one of the highly potential drugs which could treat COVID-19 patients [23, 24]. Later, based on the results of clinical trials, the drug was found to save lives of critically ill COVID patients and recommended by WHO for treatment of severe cases [25]. Another AI-biotech company, Healx, utilized its platform "Healnet" to consolidate biomedical data from varied sources and analyze it to predict effective drug combination therapies for severely ill COVID-19 patients with associated co-morbidities [26]. English company, behold. ai designed a cognitive computing platform "Red Dot" that analyzed chest X-rays to identify abnormalities and in association with Wellbeing Software, offered NHS Hospitals with the technology that enables quick diagnosis and triage of COVID-19 patients [27]. 


\section{United States Applies Analytics and Al as a Defence Against Pandemic}

As an additional line of defence against COVID-19, scientists in the worst-hit country of United States took assistance from big data, predictive analytics and cognitive computing technology. John Hopkins Center for Systems Science and Engineering (CSSE) developed an interactive dashboard displaying data through a GitHub repository to provide scientific community and general public with real-time up-to-date information on reported COVID-19 cases [28]. Institute for Health Metrics and Evaluation at the University of Washington created another dashboard with dataset enabling calculation of key statistics including incubation period, reproduction rate, etc. [29]. Google's Kaggle in collaboration with Microsoft built a platform in response to The White House Office of Science and Technology Policy's request for a data mining solution that provides an overview of scientific literature available on COVID-19 for researchers to interpret and analyze data [30, 31]. A New York-based company Tellic utilized Neo4j database to build a graph analytics platform "C19" that facilitates researchers to identify relationships and connections across scientific publications $[32,33]$. Adaptive Biotechnologies and Microsoft launched "ImmuneCODE", an open database demonstrating the population-level immune response to COVID-19 [34]. The system utilized immune medicine platform and machine learning to interpret the response of T cells to SARS-CoV-2, and generate insights to support researchers for accurate diagnosis and development of drugs.

The U.S. "HealthWeather" map, a visualization tool by Kinsa Health, produced with the analysis of data generated through its internet-connected thermometers, offered the government information about the impact of lockdown and social distancing restrictions [35]. Unacast, using its Real World Graph Data Engine, created a "Social Distancing Scoreboard" that guided authorities and public health experts about the resident behavior and mobility pattern to understand the future trend for spread of disease [36]. A similar website was developed by HealthMap at Boston Children's Hospital. COVID Near You" which encouraged public to share the information about their health status and location [37]. Mayo Clinic, along with the Minnesota Health Department created an AI tool to assess the rate of positives to negatives for a number of tests done and thereby distinguish the zones with higher transmission [38]. These initiatives enabled public health officials and even general public get a better understanding of the evolution and spread of coronavirus.

New York-based Dataminr, a company which predicts high-impact events and emerging risks, with its AI platform, published a study that predicted spikes in coronavirus cases in 14 states of the US, which later were badly affected by pandemic [39]. Apple, in association with the White House Coronavirus Task Force, the Centers for Disease Control and Prevention (CDC), and the U.S. Department of Health and Human Services (HHS) released "COVID-19 app" which utilized the information obtained from citizens, about their health and exposure, to advise the authorities of further measures on limiting the spread, screening of patients and their treatment [40]. Rimidi, an Atlanta-based digital health company, introduced an EHR-integrated app to identify potential COVID-19 patients [41].

Google DeepMind applied "AlphaFold", a system that predicted protein structure using huge genomic datasets, to anticipate the structure of SARS-CoV-2 proteins and support the researchers better understand the virus [42]. Scientists from New York University and Columbia University in collaboration with two hospitals in China created an AI tool to predict patients who would develop into severe respiratory disease and discovered the role of liver enzyme, myalgia, and hemoglobin levels in worsening of patient health [43]. Partnering with Amazon Web Services, UC San Diego Health designed and applied an AI solution to process lung X-ray images and identify patients with likelihood of developing pneumonia [44]. Moreover, researchers at Case Western Reserve University lab developed a computational tool to identify the patients with chances of developing complications and consequently in need of extensive care, to aid triage [45]. New York-based Mount Sinai Health System analyzed chest $\mathrm{CT}$ images with $\mathrm{AI}$ algorithms for rapid diagnosis of COVID-19 patients [46, 47]. Kentucky-based Baptist Health and Mayo Clinic applied remote-patient-monitoring solution by Current Health Ltd., to monitor COVID-19 patients distantly [48, 49]. Likewise, Providence Health \& Services in Washington utilized tools from Twistle to track COVID-19 patients in their homes [48]. These systems enabled the hospitals to reserve beds for critical coronavirus patients, hence curtailing some pressure.

\section{European Union Nations Use Data Analytics for Fighting COVID-19}

Telecom operators in Europe came forward to aid the national authorities in their fight against COVID-19. Vodafone, a telecom service provider, created a heat map for Lombardy region in Italy, enabling the government authorities to better track population flow [50]. Vodafone Analytics Platform which utilizes big data and AI techniques, has also been in use in Spain, Greece and Portugal [51]. The company supported administrative authorities in anticipating the impact of policy decisions on the spread of virus and burdening effects on healthcare infrastructure.

EU countries also implemented different software for rapid testing of COVID-19 patients. AI-based chest X-ray analysis solution, INSIGHT CXR by Lunit, was deployed 
in Italy, France and Portugal to help healthcare providers in triaging and management of symptomatic patients [52]. San Raffaele Hospital in Italy used a similar tool by Qure.ai called qXR which analyzed chest X-ray scan to assess the severity of virus impact on lungs [53]. Another CT image screening system, InferRead by Infervision Europe was implemented by The Campus Bio-Medico University Hospital (UCBM) to detect potential COVID19 cases [54]. Spanish Society of Anaesthesiology and Critical Care (SEDAR) approved a project by Ubikare, a bioengineering group, and scientists from 80 centers across Spain [55]. The company created "Reg Covid-19" statistical tool to provide healthcare professionals, access to datasets of coronavirus infected patients and insights on disease progression, anticipated mortality, thus enabling them take proactive decisions [56]. Spanish Government, in cooperation with Sngular, a Madrid-based tech firm, built "Hispabot-COVID19", a whatsapp-integrated chatbot to enable automated and accurate official information transmission to Spanish citizens [57].

Italian Ministry of Innovation, in cooperation with University of Pavia, used big data analytics to track lockdown compliance [58]. Anonymous datasets on users' movement were obtained from Facebook and Italian telecom companies, to aid contact tracing. Enel X, a global energy service company along with Here Technologies, a location mapping firm, developed City Analytics Mobility Map, which was used by Italian transportation agencies to evaluate mobility flows and plan containment measures [59]. Expert System, a global AI company, designed a big data solution that analyzed data from social media posts, hospital data, emergency call logs etc. to alert Italian authorities in case of alarming trends [60]. The company's Clinical Research Navigator (CRN) tool has been implemented by Inserm (France), to provide researchers with insights into latent connection between different pieces of research, by analyzing research content based on concepts [61].

France developed "StopCovid" contact tracing app which relied on Bluetooth Low Energy to track people who interacted for more than few minutes [62]. As the infected person updates a QR code on app provided by testing facility, the app notifies past two weeks of contacts about their exposure to virus. Latvia, a north European country, launched "Apturi Covid", a contact tracing app based on the toolkit provided by Apple-Google [63]. French government has also deployed DatakaLab's AI-powered video analytics tool which notifies the local transport authorities with the number of people not wearing face masks [64]. Based on the surveillance data, government can take measures like imposing fines upon violation of mandate to prevent future outbreak [65]. Researchers at the University of Barcelona produced an analogous solution. LogMask" to be used by the Spanish Government to identify if a person is wearing a mask or not [66].

German health authorities teamed up with Thryve, healthcare technology company, to design "Corona-Datenspende", an app that relied on vital signs data available from fitness trackers, to identify symptoms [67]. DZD (Deutsches Zentrum für Diabetesforschung)—German Centre for Diabetes Research-has been using graph database technology to connect different types of data, from extremely heterogeneous sources in their diabetes research [68]. To tackle the current crisis of pandemic, research center extended its graph database to apply it to coronavirus research. In collaboration with database software organizations Neo4j, YWorks and Linkurious; the diabetes center has prepared a COVID-19 graph database [69]. The availability of centralized database and analytical techniques provides opportunity to scientists, to generate hypotheses and query data for better understanding correlations between diabetes and COVID-19 disease $[69,70]$.

\section{Thorough and Prompt Measures by Singapore}

The earliest attempts by government of Singapore included launch of an app called TraceTogether to identify links between COVID-19 infected individuals and their contacts. By making use of location and proximity data with Bluetooth, the app-enabled community-driven tracing and alerted high-risk individuals [71]. Contact map was generated using different tracers with the help of digital signatures of activities like ATM card or credit card transactions to aid the assessment of nature and extent of contact between infected and others [72].

To monitor social distancing, a tech-company AI Hub Singapore designed an app SafeDistancer which combines $\mathrm{AI}$ and computer vision to monitor the distance between people by making use of phone's camera [73]. Images are processed using data analytics and an alarm rings as soon as someone comes closer, thus alerting people and helping businesses keep track of social distancing [74].

\section{South Korea's Swift Response}

As soon as South Korea identified its superspreader COVID19 patient, the government started using cellphone location data for smart contact tracing [75]. The location information was shared publicly, providing a comprehensive map of infected patient's movement and enabling people to determine the exposure and potential danger. Thereby, the system assisted authorities in reducing reaction time to identify and isolate infected patients and helped hospitals to be well prepared for future healthcare eventualities [76].

Big data analytics was also leveraged for estimating the supply and demand of coronavirus testing kits and bridging 
the gaps [77]. Artificial intelligence (AI) enabled Seoulbased molecular biotech company, Seegene to develop coronavirus test kits at accelerated rate $[76,78]$.

To assist healthcare personnel in accurate and rapid screening of patients, a medical technology company Lunit designed AI-based big data solution that analyzes large-scale chest X-ray data to classify coronavirus patients into four different categories based on the severity [76, 78]. This solution is used in South Korean coronavirus centers, where it has helped the healthcare professionals in early discovery and mainly patient triage [79]. In the coronavirus situation when hospitals are overcrowded with patients, identification of patients in critical state has been vital for the mitigating the impact of pandemic.

\section{Israel Develops Model to Predict COVID-19 Patients' Health Status}

Israeli Defence Ministry launched a study to remotely diagnose and monitor COVID-19 patients [80]. In this study, an app developed by Vocalis Health was utilized to analyze "voice fingerprints", allowing hospitals to diagnose infected patients remotely without exposing and risking healthcare workers. Rambam Hospital in Haifa utilized Cordio Medical's app based on the same principle of speech analysis to identify patients having bilateral pneumonia with edema and thereby diagnose COVID-19 [81]. Sheba Medical Center and the Ichilov Hospital at Tel Aviv Sourasky Medical Center deployed a TeleICU solution based on predictive analytics to identify severity of disease and enable healthcare providers to proactively manage the patients and hospital resources [82]. Maccabi Healthcare Service in partnership with Medial EarlySign developed a system that identifies at-risk COVID-19 patients and determines the level of treatment required [83]. Scientists from Israel Aerospace Industries (IAI) designed an AI-based model that predicted the progression of disease [84]. By alerting the medical workers of possible deterioration, the system allowed better patient care and improved patient outcomes.

\section{Australia's Use of Big Data for Decision-making}

With a focus on dealing with the COVID-19 crisis, Australian government tapped into big data analytics. The government increased its external spending on COVID-19 data analytics from Quantium Health Pty Ltd., a data science consultancy firm in March 2020 [85]. By employing analytical tools, models were designed to explore the impact of social distancing, quarantine and self-isolation, on spread of infection and eventually on overloading of healthcare systems. Economic models were applied to determine measures for reducing the detrimental effect of pandemic on businesses. Analysis of COVID-19 big data, thus, fuelled the strategic planning by aiding decision-making on different levels, from augmenting the healthcare infrastructure capacity to closure of industries and services, and sealing of borders for limiting the effect of coronavirus [86].

\section{United Arab Emirates (UAE) Deploys Technology to Curb Spread}

Responding to coronavirus situation, UAE has been using AI, big data and internet-connected devices at different levels for tracking, testing and monitoring compliance to lockdown rules [87]. Internet-connected devices have helped government keep check if citizens are abiding by 'social distancing' rules. Dubai Police has been using a platform called 'Oyoon' which analyzes data from facial, voice and license plate recognition to monitor if a citizen holds a valid permit and, thus, regulates the movement of residents [88]. Abu Dhabi Health Services Company (SEHA) collaborated with Draper \& Dash, a Britain based firm, to analyze data for predicting the spread of coronavirus, anticipating the demand for medical facilities, gauging their clinical capacity and planning the actions accordingly [89].

Healthcare startup-Nabta Health—has been utilizing AI solutions to identify symptoms and evaluate risks on the basis of underlying health conditions [89]. Nybl, a Dubaibased tech company, provided AI and big data technologies to the government to facilitate management of health supplies. These solutions enabled the matching of supply to demand by identifying the available resources and hospital needs and procuring stocks as per the necessity [87]. Another Abu Dhabi-based AI company, Group 42 (G42), in cooperation with various organizations has been employing technology for testing and research [89]. A COVID-19 detection lab was developed by the company in association with a global genome sequencing organization, BGI, to scale RT-PCR testing and diagnosis to the population level [90]. The company also provides other tools for rapid virus genome analysis, CT scan evaluation for COVID-19 and pneumonia, and in silico drug discovery to reduce drug testing duration [91].

\section{India Initiates COVID-19 ‘National Supermodel’ to Support Decision-making}

The early response of Indian government towards pandemic was a country-wide lockdown, followed by the use of 'Aarogya Setu', a coronavirus tracking app, which used location and Bluetooth data to determine if the person has been in vicinity of an infected person [92]. Thereafter, Larsen \& Toubro, an engineering company, harnessed AI and analytics to aid 20 Indian cities for crowd monitoring and alerting the authorities to disperse the crowd when needed [93]. The organization also offered automated number plate 
recognition system to assist Hyderabad police in ensuring compliance to administrative order of restricted movement [94].

Some of the states leveraged analytical technology for detection and surveillance. Where Kerala employed AI-enabled thermal scanner for screening; Karnataka applied these tools to keep a check on patients under quarantine; Uttar Pradesh took assistance from Staqu [95], an AI company, to analyze videos for monitoring social distancing protocol compliance; Bihar, through its Norway India Partnership Initiative (NIPI), utilized cough sound analysis tool to identify potential patients; and Tamil Nadu made use of analytical solutions for hospital inventory management, implementation of quarantine orders and call center operations [93]. In Maharashtra, Municipal Corporation of Greater Mumbai (MCGM) partnered with Qure.ai to deploy COVID-19 bus equipped with AI tools and medical testing facilities, for extensive screening based on X-ray analysis, in high-risk areas [96].

Apollo Hospitals Group, collaborated with Behold.ai, a UK-based AI radiology company, to identify suspected COVID-19 patients [97]. The 'instant triage' solution offered by the company differentiated abnormal chest X-ray images from normal in $30 \mathrm{~s}$, thus assisting the medical professionals in prioritizing care delivery. A similar solution available free on the internet was developed by Researchers at the Defence Institute of Advanced Technology (DIAT) in Pune, where upon uploading chest X-ray images, the system promptly confirmed if there is any abnormality because of COVID19 or other respiratory diseases [98]. Researchers at Indian Institute of Technology (IIT) - Hyderabad, developed a lowcost AI-powered test kit that instead of RT-PCR, utilized genome sequencing technique, to identify conserved region of COVID-19 genome and deliver test results in $20 \mathrm{~min}$ [99].

On the other side, the Department of Science and Technology (DST) launched COVID-19 'National Supermodel', a forecasting model based on predictive analytics, for disease surveillance and anticipating the spread of coronavirus [100]. With cooperative efforts of DST, Jawaharlal Nehru Centre for Advanced Scientific Research (JNCASR) and IISc-Bangalore, the developed model would predict the rate of spread of the infection and its burdening effect on healthcare system, thus facilitating better-informed policy decision-making.

\section{Findings and Discussion}

\section{Big Data Analytics and AI Application Initiatives}

To address the prodigious impact of COVID-19 on health, economics and everyday life, governments and various organizations in different nations took aid of diverse advanced analytical tools (Fig. 2). Contact tracing applications have been widely used by them to understand the virus transmission and spread. Most of the countries, globally, have also utilized analytical tools for diagnosis and monitoring of COVID-19 infected patients. In some nations, organizations employed big data analytics for clinical research and accelerating drug discovery and development. Cognitive analytics was also put to use by countries for shaping healthcare governance and better decision support. This included applications such as ensuring flow of accurate and up-to-date information; identification of areas with need for medical resources and ensuring adequate distribution; determination of need for quarantine; and formulating resilience strategies for COVID-19. These big data analytics and AI application initiatives by various countries are summarized in Table 1 .

\section{Challenges and Perils of Data-Driven Measures to Combat the Pandemic}

Besides bringing varied possibilities to deal with the universal crisis, big data and predictive analytics technology also
Fig. 2 Big data analytics and AI initiatives used by nations for pandemic preparedness and response

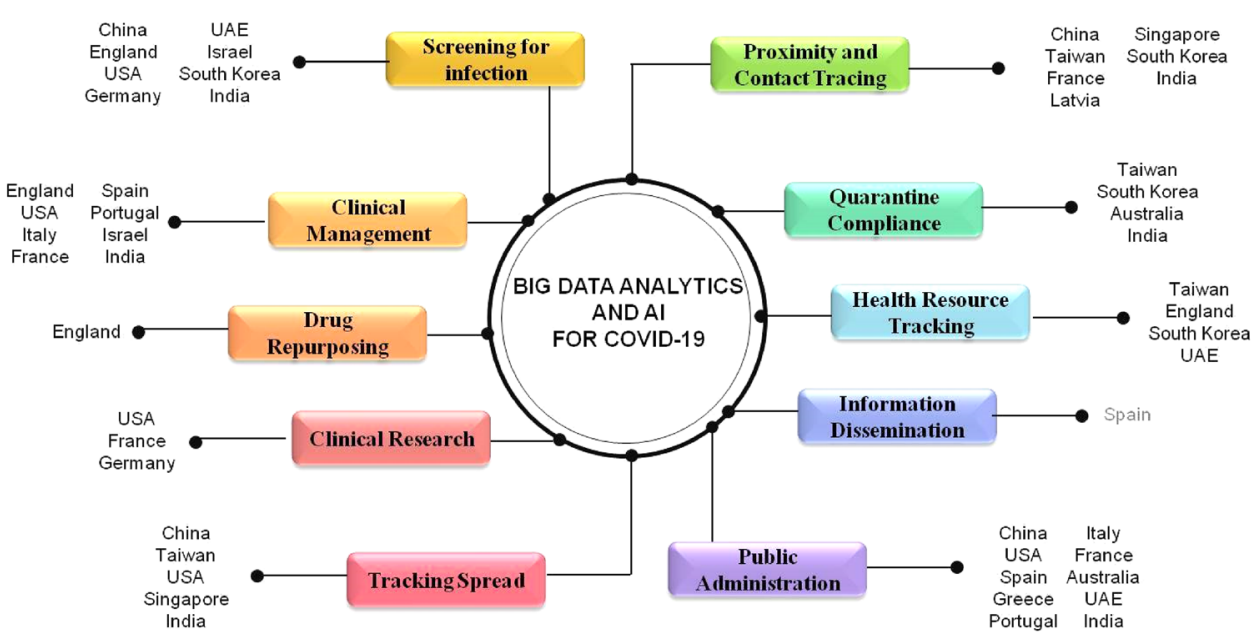

SN Computer Science A SPRINGER NATURE journal 







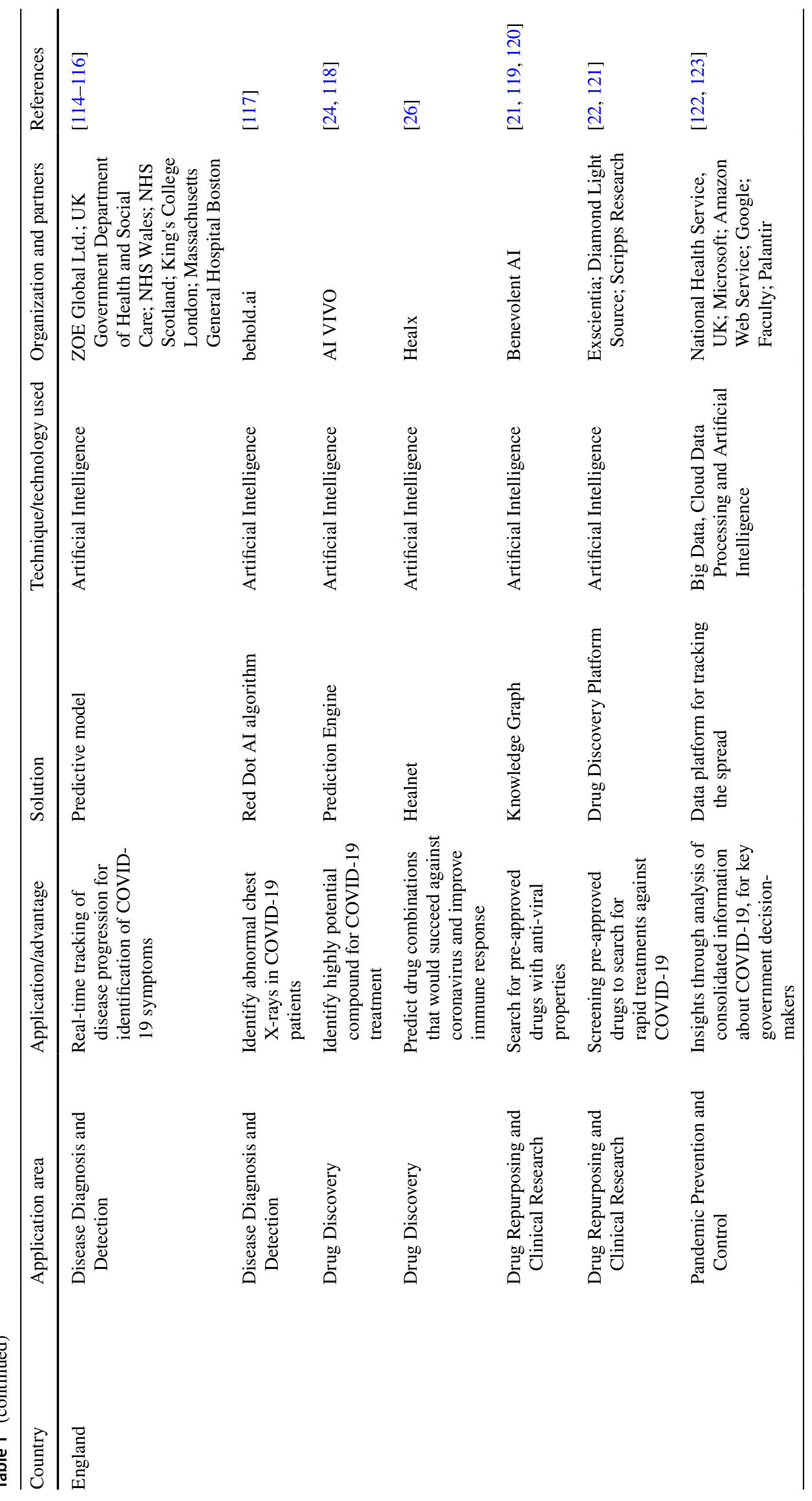




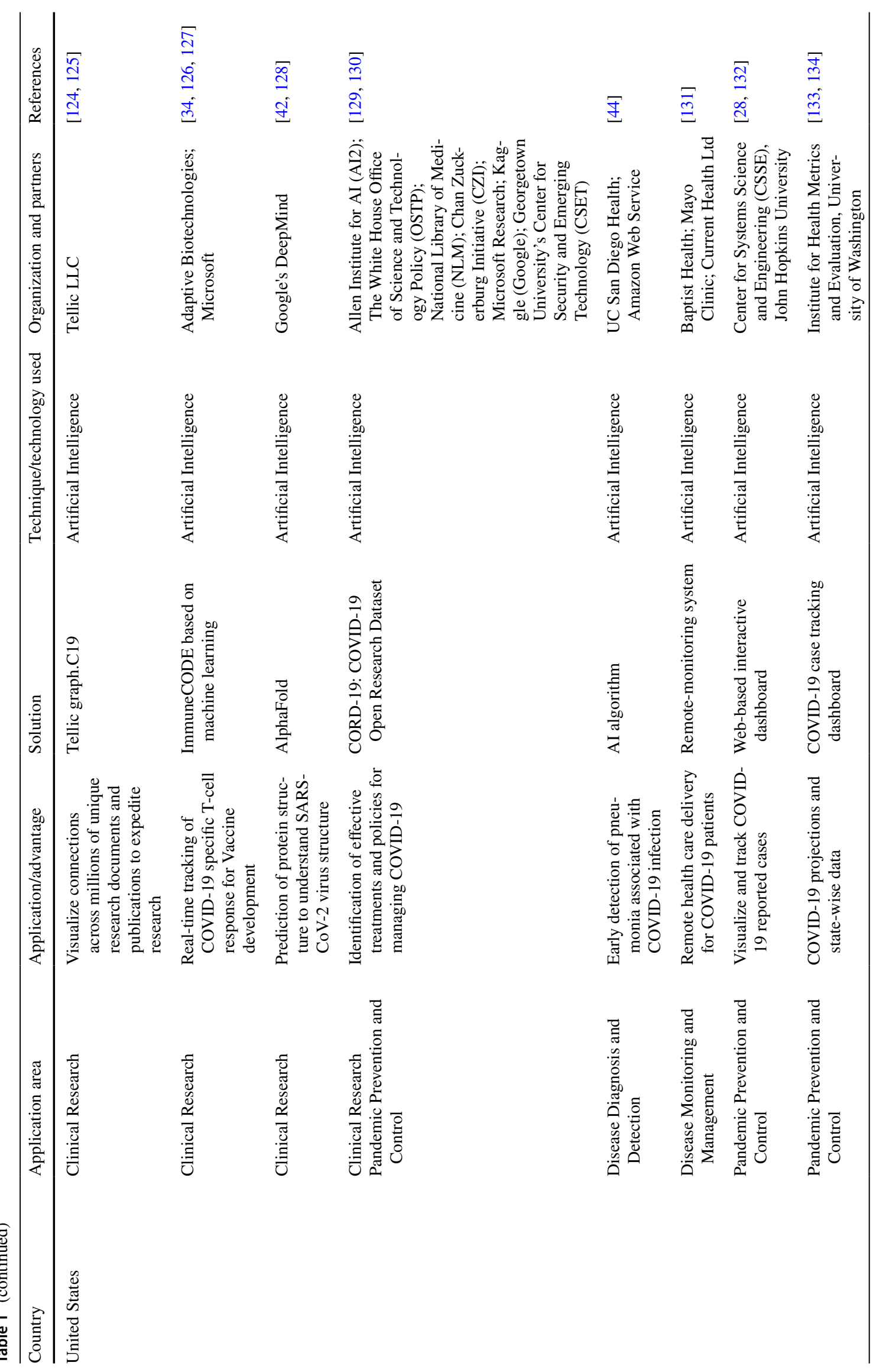




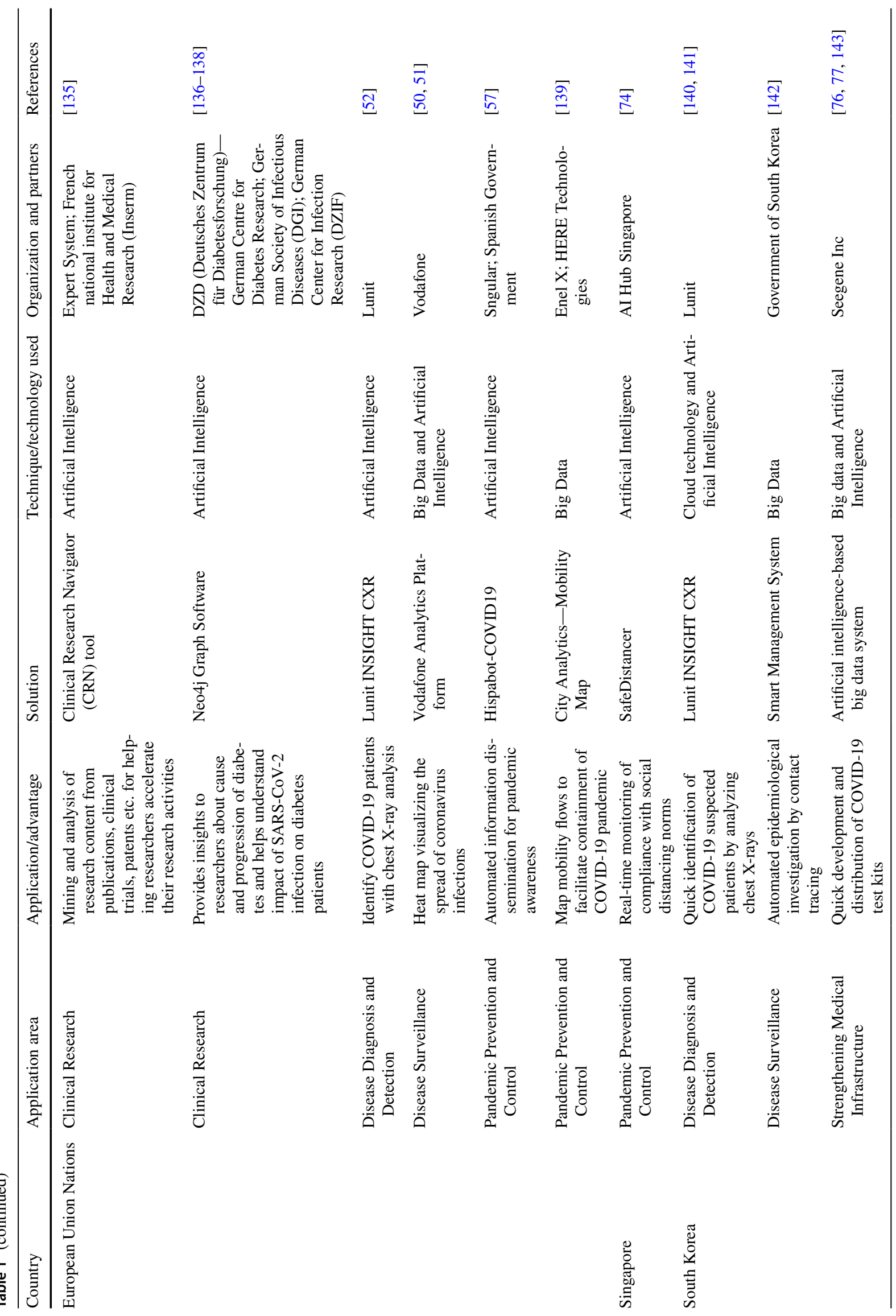




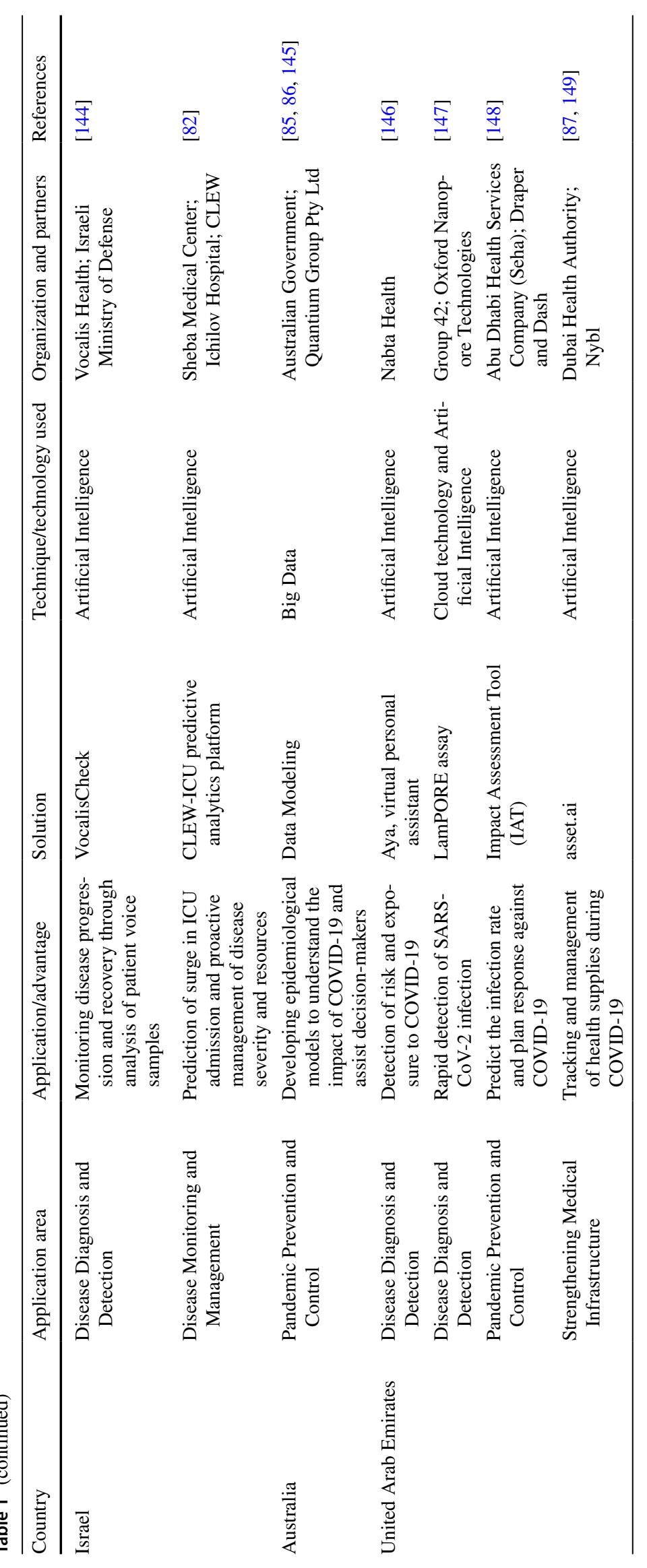

SN Computer Science

A SPRINGER NATURE journal 


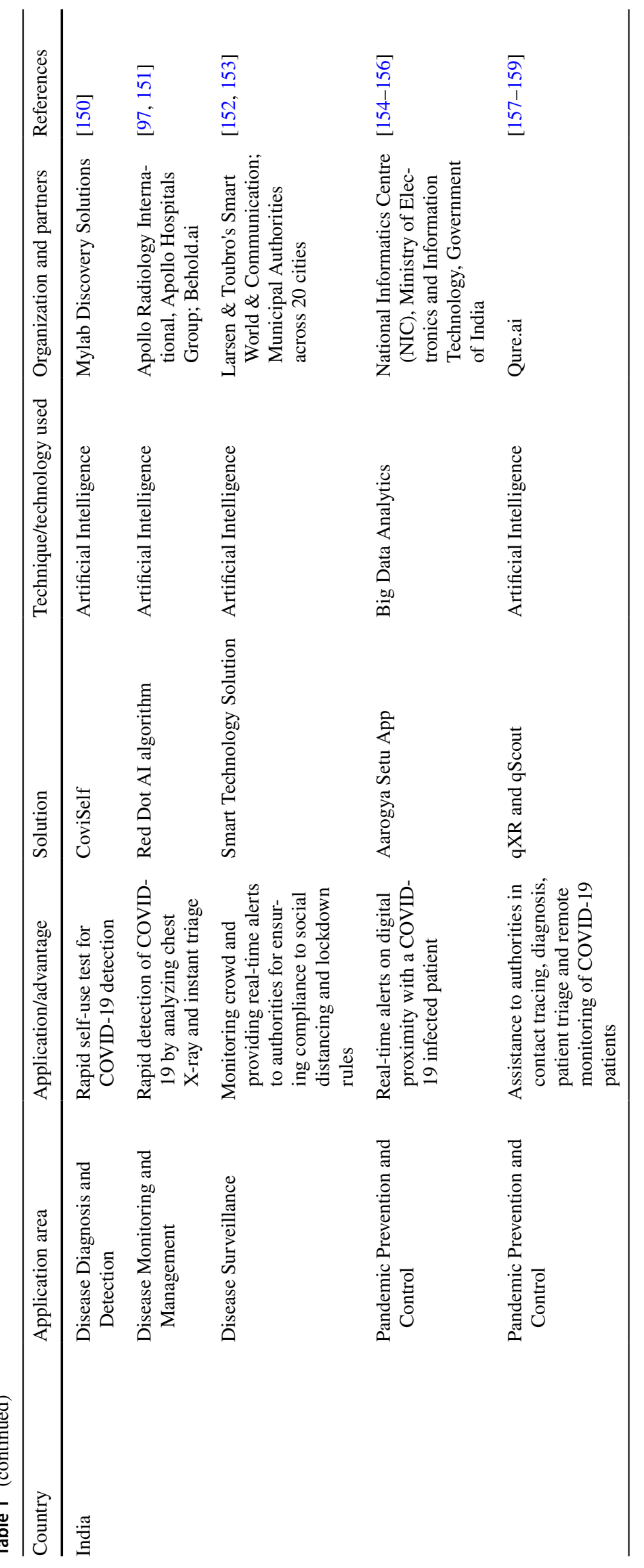


brings certain challenges in its application. Some of these challenges are discussed below:

\section{Lack of Historical Data}

Due to the novelty of SARS-CoV-2 virus, there has been limited evidence about its transmission, incubation period, associated pathophysiology and duration of infection [1, 160]. There is also a paucity of data on the extent of protection, duration of immunity and chances of re-infection after contracting COVID-19 [161]. Moreover, the genetic evolution of virus and development of different mutant variants over time makes predicting COVID-19 incidence and outcomes, further difficult because of lack of availability of historical data $[162,163]$.

\section{Interoperability and Access to Real-Time Data}

Since pre-COVID, one of the major barriers in effective use of data in healthcare has been the lack of cross-system interoperability and this has further amplified during the pandemic. The siloed nature of ubiquitous technologies in healthcare has restricted real-time access to COVID-19 treatment and clinical trials data [164-166]. Capturing, documentation, distribution and sharing of healthcare data across different hospitals and government bodies, therefore, would also require a manual compilation in spreadsheets for better monitoring and management of the crisis [167]. In the current state of pandemic, spending more time and resources on recording and exchanging data, would delay the response and cost hundreds of lives.

\section{Data Sharing}

Given the urgency to accelerate effective response to COVID-19, there was a need for governments, public health agencies and private organizations to promote data sharing initiatives [168]. Most of the nations encountered issues with inadequate data exchange. The primary challenge these organizations faced was consolidation of the data that differed in its characteristic and extent [163]. Other problems that hampered effective data exchange include legal issues, limited financial support and international communication [169]. On the other hand, some of the organizations and research communities created integrated platform models and open-source structures to enable frictionless data sharing resulting in extensive amount of research and therapeutic data [169].

\section{Data Quality}

When it comes to the healthcare data, quality of data is of utmost importance. Growing amount of data added with the demand for prompt response to the pandemic, makes it difficult to guarantee high quality data that can be relied on to for safe medical care $[170,171]$. Incomplete and poorquality data aggregated from different sources in varied formats, results in development of inaccurate predictive models and hinders its use for effective policy decisionmaking [163, 170]. For instance, detection of COVID-19 through chest X-ray or CT image analysis is also not completely dependable, because in some infected patients, the results yield normal chest image; while in other cases, the abnormalities are connected with separate pathological conditions [172].

\section{Privacy and Security of Data}

With the increasing amount of COVID-19 data being continuously created, some newer challenges arise [164]. One such challenge was encountered by the countries that relied on the geographical location data to track the spread of virus. Implementation of contact tracing applications to understand and predict the spread of COVID-19 has raised the concern about exposing the sensitive personal health information and jeopardizing privacy [173, 174]. Moreover, exchange and aggregation of medical data from different sources pose threat to security of healthcare data [175]. There have been instances where cybercriminals were identified phishing the organizations involved in COVID-19 vaccine research, development and distribution [176, 177]. In this time of pandemic, when there is a need for rapid response, regulatory authorities are required to define policies that allow reaping the rewards of technology at the same time ensuring the privacy and security of data.

\section{Limitations of the Study}

The field of big data and advanced analytics is rapidly evolving since the time world is facing the coronavirus pandemic. First, owing to the recentness of these applications in dealing with the global emergency, this study derives information majorly from news articles. Such information does not enable differentiating the proposals from those solutions which have been put into practice, making it a limitation in understanding the real use of data analytics. Second, this review provides an overview of country-specific measures taken by those nations which are either gravely affected or those which have addressed the crisis at its onset and avoided the larger damage. Given the focus on such countries, the study might have missed instances where other governments and organizations would have exploited big data technologies in their COVID-19 combat. 


\section{Conclusion}

Emergence of SARS-CoV-2, no prior knowledge about its structure and behavior, and its higher rate of transmission have all led to the governments and organizations turning towards technology for prompt management of the crisis. Several measures are being utilized by governments and other organizations for application of big data and advanced analytics: be it for prediction of outbreak, detection and diagnosis of infected patients, anticipation of critical cases; or decision support in what treatment would work well for which kind of patients; what measures would curb the spread; and planning the future action. Big data and AI have also augmented the research activities by simulating the viral morphology and its evolution; and providing quicker identification of potential drug candidates for treatment of COVID-19 patients. Furthermore, these technologies have proven useful for hospitals in predicting the demand for healthcare resources and planning the allocation in advance. In these unprecedented times, big data and AI empower countries and the governing authorities with solutions that can reduce the impact of virus and be instrumental in effective planning to address immediate public health challenges.

\section{Funding None.}

\section{Declarations}

Conflict of interest Authors have no conflict of interest.

\section{References}

1. Anderson RM, Heesterbeek H, Klinkenberg D, Hollingsworth TD. How will country-based mitigation measures influence the course of the COVID-19 epidemic? Lancet. 2020;395:931-4.

2. Sogn D (2020) Pandemic analytics: how data is helping us combat COVID-19. https://www.hcltech.com/blogs/pandemicanalytics-how-data-and-analytics-can-help-us-combat-covid-19. Accessed 10 Jun 2020

3. DHS Science and Technology (2020) Master question list for COVID-19 (caused by SARS-CoV-2). https://www.dhs.gov/publi cation/st-master-question-list-covid-19. Accessed 23 Dec 2020

4. Niller E (2020) An aI epidemiologist sent the first warnings of the wuhan virus. In: wired. https://www.wired.com/story/aiepidemiologist-wuhan-public-health-warnings/. Accessed 25 Dec 2020

5. IANS (2020) Tech firms using big data to help fight novel coronavirus. In: Bus. Insid. https://www.thehindu.com/sci-tech/techn ology/tech-firms-using-big-data-to-help-fight-novel-coronavirus/ article30724513.ece. Accessed 29 Dec 2020

6. CGTN (2020) Big data plays major role in fight against COVID19. https://news.cgtn.com/news/2020-02-21/Big-data-playsmajor-role-in-fight-against-COVID-19-OgSu21VP3O/index. html. Accessed 28 Dec 2020
7. Xinhua (2020) China Focus: Big data enlisted in China's fight against coronavirus. https://www.xinhuanet.com/english/202002/05/c_138757865.htm. Accessed 3 Jan 2021

8. World Health Organization. WHO Coronavirus (COVID-19) Dashboard. 2021. https://covid19.who.int/. Accessed 05 Jul 2021.

9. Mozur P, Zhong R, Krolik A (2020) In Coronavirus Fight, China Gives Citizens a Color Code, With Red Flags. In: NY Times. https://www.nytimes.com/2020/03/01/business/china-coronavirus-surveillance.html. Accessed 7 Jan 2021

10. Healthcare-in-europe.com (2020) China uses AI to combat the novel coronavirus outbreak. https://healthcare-in-europe.com/en/ news/china-uses-ai-to-combat-the-novel-coronavirus-outbreak. html. Accessed 17 Jan 2021

11. Alibaba Cloud. CT Image Analytics for COVID-19. 2020. https://www.alibabacloud.com/solutions/ct-image-analytics. Accessed 15 Mar 2021.

12. ITU News (2020) COVID-19: China's digital health strategies against the global pandemic. https://news.itu.int/covid19-chinas-digital-health-strategies-against-the-global-pande micl. Accessed 20 Jan 2021

13. Wang CJ, Ng CY, Brook RH. Response to COVID-19 in Taiwan: big data analytics, new technology, and proactive testing. JAMA J Am Med Assoc. 2020;323(14):1341-2.

14. Broga D (2020) How Taiwan used tech to fight COVID-19. In: Tech UK. https://www.wired-gov.net/wg/news.nsf/articles/ How+Taiwan+used+tech+to+fight+COVID19+0104202016 2500?open. Accessed 26 Jan 2021

15. Lee Y (2020) Taiwan's new "electronic fence" for quarantines leads wave of virus monitoring. In: Reuters. https://www. reuters.com/article/us-health-coronavirus-taiwan-surveillancidUSKBN2170SK. Accessed 28 Jan 2021

16. Wei K (2020) Health Minister gains fans even as Taiwan grapples with evacuation quandary, new coronavirus cases. In: The Straits Times. https://www.straitstimes.com/asia/east-asia/ health-minister-gains-fans-even-as-taiwan-grapples-with-evacu ation-quandary-new. Accessed 30 Jan 2021

17. Verdict (2020) NHS turns to big data, AI and the cloud to stem coronavirus. Verdict (2020) NHS turns to big data, AI and the cloud to stem coronavirus. Accessed 3 Feb 2021

18. Gould M, Joshi DI, Tang M (2020) The power of data in a pandemic. In: Gov.UK. https://healthtech.blog.gov.uk/2020/03/ 28/the-power-of-data-in-a-pandemic/. Accessed 21 Sep 2021

19. HospiMedica International (2020) New Artificial Intelligence Algorithm Accurately Predicts COVID-19 Without Testing. https://www.hospimedica.com/covid-19/articles/294782353/ new-artificial-intelligence-algorithm-accurately-predictscovid-19-without-testing.html. Accessed 10 Feb 2021

20. NHS Digital (2020) Trials begin of machine learning system to help hospitals plan and manage COVID-19 treatment resources developed by NHS Digital and University of Cambridge. https://digital.nhs.uk/news/2020/trials-begin-of-machi ne-learning-system-to-help-hospitals-plan-and-manage-covid19-treatment-resources-developed-by-nhs-digital-and-unive rsity-of-cambridge. Accessed 16 Feb 2021

21. Richardson $P$, et al. Baricitinib as potential treatment for 2019-nCoV acute respiratory disease. Lancet. 2020;395(10223):e30-1.

22. Exscientia (2020) Exscientia announces joint initiative to identify COVID-19 drugs with Diamond Light Source and Scripps Research. In: Exscentia. https://www.exscientia.ai/news-insig hts/exscientia-announces-joint-initiative-to-identify-covid-19. Accessed 21 Sep 2021

23. Business Wire (2020) Dexamethasone identified by AI VIVO as high potential for treatment of COVID-19 ten weeks ago. https:// www.businesswire.com/news/home/20200618005360/en/Dexam 
ethasone-identified-by-AI-VIVO-as-high-potential-for-treatmentof-COVID-19-ten-weeks-ago. Accessed 18 Feb 2021

24. HospiMedica International (2020) AI Platform Identifies Top Candidate Drugs for Treatment of COVID-19. In: HospiMedica Int. https://www.hospimedica.com/covid-19/articles/294781781/ ai-platform-identifies-top-candidate-drugs-for-treatment-ofcovid-19.html. Accessed 21 Sep 2021

25. Organization WH (2020) WHO welcomes preliminary results about dexamethasone use in treating critically ill COVID-19 patients. https://www.who.int/news/item/16-06-2020-who-welco mes-preliminary-results-about-dexamethasone-use-in-treatingcritically-ill-covid-19-patients. Accessed 21 Feb 2021

26. Healx. Healx using artificial intelligence to find combination drug treatments for COVID-19. Healx, 2020. https://healx.io/ healx-using-ai-to-find-combination-drug-treatments-for-covid19/. Accessed 19 Dec 2020.

27. Behold.ai (2020) behold.ai and Wellbeing Software collaborate on national solution for rapid COVID-19 diagnosis using AI analysis of chest X-rays. https://www.globenewswire.com/ news-release/2020/03/31/2008864/0/en/behold-ai-and-Wellb eing-Software-collaborate-on-national-solution-for-rapidCOVID-19-diagnosis-using-AI-analysis-of-chest-X-rays.html. Accessed $23 \mathrm{Feb} 2021$

28. Dong E, Du H, Gardner L. An interactive web-based dashboard to track COVID-19 in real time. Lancet Infect Dis. 2020;20(5):533-4.

29. Roser M, Ritchie H, Ortiz-Ospina E, Hasell J (2020) Coronavirus pandemic (COVID-19). In: OurworldIndata.org. https://ourwo rldindata.org/coronavirus. Accessed $25 \mathrm{Feb} 2021$

30. Office of science and technology policy (2020) Call to action to the tech community on new Machine readable COVID-19 dataset. https://trumpwhitehouse.archives.gov/briefings-statements/ call-action-tech-community-new-machine-readable-covid-19dataset/. Accessed 27 Feb 2021

31. Saran C (2020) Microsoft and google join forces on Covid-19 dataset. In: Comput. Wkly. https://www.computerweekly.com/ news/252480156/Microsoft-and-Google-join-forces-on-Covid19-dataset. Accessed 28 Feb 2021

32. Roby K (2020) Big data graphs are playing an important role in the coronavirus pandemic. In: Tech Repub. https://www.techr epublic.com/article/big-data-graphs-are-playing-an-importantrole-in-the-coronavirus-pandemic/. Accessed 2 Mar 2021

33. Tellic. Register for your free access to tellic graph.C19 that is now available to help expedite your COVID-19 research. 2020.

34. Microsoft. Adaptive Biotechnologies and Microsoft launch groundbreaking ImmuneCODE database to share populationwide immune response to the COVID-19 virus. Microsoft, 2020. https://news.microsoft.com/2020/06/11/adaptive-biotechnol ogies-and-microsoft-launch-groundbreaking-immunecode-datab ase-to-share-populationwide-immune-response-to-the-covid-19virus/. Accessed 23 Dec 2020.

35. McNeil DG (2020) Restrictions Are Slowing Coronavirus Infections, New Data Suggest. In: NewYork Times. https://www.nytim es.com/2020/03/30/health/coronavirus-restrictions-fevers.html. Accessed 4 Mar 2021

36. PR Newswire (2020) Unacast Launches Pro Bono Social Distancing Scoreboard as Part of COVID-19 Toolkit. https://marte chseries.com/analytics/behavioral-marketing/location-data/unaca st-launches-pro-bono-social-distancing-scoreboard-part-covid19-toolkit/. Accessed 6 Mar 2021

37. Fliesler N (2020) Crowdsourcing the COVID-19 pandemic in real time. In: Bost. Child. Hosp. https://answers.childrenshospit al.org/covid-near-you-coronavirus-tracking/. Accessed 6 Mar 2021

38. Drees J (2020) Mayo clinic uses aI to map COVID-19 hot zones. https://www.beckershospitalreview.com/artificial-intelligence/ mayo-clinic-uses-ai-to-map-covid-19-hot-zones.html. Accessed 7 Mar 2021

39. Dataminr (2020) Dataminr COVID-19 U.S. study. https://www. dataminr.com/covid19-us. Accessed 8 Mar 2021

40. Centers for Disease Control and Prevention (2020) CDC Statement on COVID-19 Apple App, Press Release. https://www.cdc. gov/media/releases/2020/s0327-statement-covid-19-apple-app. html. Accessed 9 Mar 2021

41. Keough E (2020) Rimidi Unveils New App to Accelerate Patient Screenings for COVID-19. In: Rimidi. https://rimidi.com/news/ rimidi-unveils-new-app-to-accelerate-patient-screenings-forcovid-19. Accessed 10 Mar 2021

42. DeepMind. Computational predictions of protein structures associated with COVID-19. 2020. https://deepmind.com/research/ open-source/computational-predictions-of-protein-structuresassociated-with-COVID-19. Accessed 16 Sep 2020.

43. Williams G (2020) Artificial intelligence tool predicts which patients with pandemic virus will develop serious respiratory disease. https://nyulangone.org/news/artificial-intelligence-toolpredicts-which-patients-pandemic-virus-will-develop-seriousrespiratory-disease. Accessed 11 Mar 2021

44. Buschman H. Artificial intelligence enables rapid COVID-19 lung imaging analysis at UC San Diego health. UC San Diego Health. 2020. https://health.ucsd.edu/news/releases/Pages/202004-07-artificial-intelligence-enables-rapid-covid-19-lung-imagi ng-analysis.aspx. Accessed 23 Oct 2020.

45. Madabhushi A (2020) Researchers using artificial intelligence to find out which COVID-19 patients are most likely to need ventilators. https://thedaily.case.edu/researchers-using-artificial-intel ligence-to-find-out-which-covid-19-patients-are-most-likely-toneed-ventilators/. Accessed 12 Mar 2021

46. Jercich K (2020) Researchers at mount sinai use aI to detect COVID-19 in lung scans. https://www.healthcareitnews.com/ news/researchers-mount-sinai-use-ai-detect-covid-19-lung-scans. Accessed 14 Mar 2021

47. Fayad ZA (2020) Mount sinai first in U.S. to use artificial intelligence to analyze coronavirus (COVID-19) patients. In: Mt. Sinai. https://www.mountsinai.org/about/newsroom/2020/mount-sinaifirst-in-us-to-use-artificial-intelligence-to-analyze-coronaviruscovid19-patients-pr. Accessed 14 Mar 2021

48. Rosenbush S (2020) Hospitals monitor some coronavirus patients at home. In: WSJ. https://www.wsj.com/articles/hospitals-monit or-some-coronavirus-patients-at-home-11586856604. Accessed 16 Mar 2021

49. Wiggers K (2020) Current health partners with the mayo clinic for remote coronavirus patient monitoring. In: Venturebeat. https://venturebeat.com/2020/04/29/current-health-partnerswith-the-mayo-clinic-for-remote-coronavirus-patient-monit oring/. Accessed 17 Mar 2021

50. Vodafone (2020) Vodafone launches five-point plan to help counter the impacts of the COVID-19 outbreak. https://www.sec.gov/ Archives/edgar/data/839923/000110465920035039/a20-13104_ 16k.htm. Accessed 17 Mar 2021

51. Reiter J (2020) Correct use of telco data can help in this crisis. In: Vodafone. https://www.politico.eu/sponsored-content/corre ct-use-of-telecom-data-can-help-in-this-crisis/. Accessed 18 Mar 2021

52. ITN Online (2020) Lunit's aI solution for COVID-19 has users in over 10 countries. https://www.itnonline.com/content/lunitsai-solution-covid-19-has-users-over-10-countries. Accessed 20 Mar 2021

53. Innovation MT (2020) AI-solutions player to help monitor COVID-19 patients in Italy. https://www.med-technews.com/ news/ai-solutions-player-to-help-monitor-covid-19-patients-inita/. Accessed 21 Mar 2021 
54. Newswire (2020) Infervision's AI is in Italy Helping to Battle COVID-19. https://www.newswire.com/news/infervisions-ai-isin-italy-helping-to-battle-covid-19-21115608. Accessed $22 \mathrm{Mar}$ 2021

55. Herrera JT, Tamayo G, Hernández-Sanz ML, Ferrando C (2020) Newsletter June 2020 Issue: SEDAR-Ubikare prospective dataset for COVID-19 critically ill patients. In: Eur. Soc. Anaesthesiol. https://www.esaic.org/esa-news/newsletter-june-2020-issuesedar-ubikare-prospective-dataset-for-covid-19-critically-illpatients/. Accessed 22 Mar 2021

56. Capitán B (2020) Ubikare desarrolla la herramienta reg CoVid19 que se usa ya en más de 50 hospitales españoles. https://elref erente.es/innovadores/ubikare-desarrolla-la-herramienta-regcovid-19-que-se-usa-ya-en-mas-de-50-hospitales-espanoles/. Accessed 23 Mar 2021

57. PR Newswire (2020) Government sets up hispabot-Covid19, a channel for enquiries about COVID-19 through whatsApp. https://www.lamoncloa.gob.es/lang/en/gobierno/news/Paginas/ 2020/20200408covid-assistance.aspx. Accessed 24 Mar 2021

58. Privacy International (2020) Italy: Telcos turn over anonymised location data to aid contact tracing. https://privacyinternational. org/examples/3422/italy-telcos-turn-over-anonymised-locationdata-aid-contact-tracing. Accessed 25 Mar 2021

59. Stone T (2020) Covid 19: Italian transport authorities to benefit from free analytics software. In: Traffic Technol. Today. https:// www.traffictechnologytoday.com/news/covid-19-news/covid-19italian-transport-authorities-to-benefit-from-free-analytics-softw are.html. Accessed 26 Mar 2021

60. Tognini G (2020) The italian aI firm helping governments fight coronavirus - and spot the next pandemic. In: Forbes. https:// www.forbes.com/sites/giacomotognini/2020/04/23/the-italianai-firm-helping-governments-fight-coronavirus---and-spot-thenext-pandemic/. Accessed 26 Mar 2021

61. Mageit S (2020) Inserm selects expert system's artificial intelligence to support COVID-19 research. In: Healthc. IT news. https://www.healthcareitnews.com/news/emea/inserm-selec ts-expert-systems-artificial-intelligence-support-covid-19-resea rch. Accessed 27 Mar 2021

62. Dillet R (2020) France releases contact-tracing app StopCovid. In: TechCrunch. https://techcrunch.com/2020/06/02/france-relea ses-contact-tracing-app-stopcovid-on-android/. Accessed $28 \mathrm{Mar}$ 2021

63. Euractive, Reuters (2020) Latvia to launch google-apple friendly coronavirus contact tracing app. https://www.reuters.com/article/ us-health-coronavirus-tech-latvia-idUSKBN23118I. Accessed 28 Mar 2021

64. Vincent J (2020) France is using AI to check whether people are wearing masks on public transport. In: The Verge. https:// www.theverge.com/2020/5/7/21250357/france-masks-public-transport-mandatory-ai-surveillance-camera-software. Accessed 30 Mar 2021

65. Fouquet H (2020) Paris tests face-mask recognition software on metro riders. In: Bloomberg. https://www.bloomberg.com/ news/articles/2020-05-07/paris-tests-face-mask-recognitionsoftware-on-metro-riders. Accessed 31 Mar 2021

66. Lewis D. Spanish government are said to be interested in the technology in a way to prove who is flouting the Covid-19 rules. RTN Newspaper; 2020.

67. Feng C (2020) Germany turns to fitness-tracking app to help monitor coronavirus infections nationwide. https://www.scmp. com/tech/apps-social/article/3079035/germany-turns-fitnesstracking-app-help-monitor-coronavirus. Accessed 2 Apr 2021

68. neo4j (2019) German centre for diabetes research case study. https://neo4j.com/case-studies/german-centre-diabetes-resea rch-dzd/. Accessed 5 Apr 2021
69. McKenna B (2020) German diabetes institute uses graph database to connect coronavirus research. In: Comput. Wkly. https://www.computerweekly.com/news/252481355/Germandiabetes-institute-uses-graph-database-to-connect-coronavirusresearch. Accessed 7 Apr 2021

70. Eifrem E (2018) Diabetes Research Using New Data Models Makes Fresh Research Connections. J Clin Stud 10:16-17

71. Holmes A (2020) Singapore is using a high-tech surveillance app to track the coronavirus, keeping schools and businesses open. Here's how it works. In: 2bus. Insid. https://www.busin essinsider.in/tech/news/singapore-is-using-a-high-tech-surve illance-app-to-track-the-coronavirus-keeping-schools-andbusinesses-open-heres-how-it-works-/articleshow/74797714. cms. Accessed 7 Apr 2021

72. Wharton School (2020) Combating COVID-19: Lessons from singapore, south korea and taiwan. https://knowledge.wharton. upenn.edu/article/singapore-south_korea-taiwan-used-techn ology-combat-covid-19/. Accessed 8 Apr 2021

73. Girling W (2020) AI Hub Singapore creates COVID-19 monitoring app. In: Bus. Chief. https://businesschief.asia/techn ology/ai-hub-singapore-creates-covid-19-monitoring-app. Accessed 9 Apr 2021

74. AI Hub Singapore. AI Hub Singapore creates first AI computer vision application that allows businesses to monitor social distancing with a mobile phone. PR Newswire. 2020. https:// www.prnewswire.com/news-releases/ai-hub-singapore-createsfirst-ai-computer-vision-application-that-allows-businesses-tomonitor-social-distancing-with-a-mobile-phone-301052610. html. Accessed 13 Oct 2020.

75. Lyons K (2020) Governments around the world are increasingly using location data to manage the coronavirus. In: The Verge. https://www.theverge.com/2020/3/23/21190700/eumobile-carriers-customer-data-coronavirus-south-korea-taiwan-privacy. Accessed 10 Apr 2021

76. Dzuroska F. Coronavirus: a big data lesson from South Korea. Towards Data Science, 2020. https://towardsdatascience.com/ coronavirus-a-big-data-lesson-from-south-korea-5bb703b8b0 ae. Accessed 18 Aug 2020.

77. Analytics Insight. Utilizing the big data card in the time of coronavirus pandemic. 2020. https://www.analyticsinsight.net/ utilizing-bigdata-card-time-coronavirus-pandemic/. Accessed 14 Aug 2020.

78. Srivastava S (2020) How Coronavirus Contributes to Catalysing South Korea's AI Aspirations? In: Anal. Insight. https:// www.analyticsinsight.net/coronavirus-contributes-catalysingsouth-koreas-ai-aspirations/. Accessed 12 Apr 2021

79. Lunit (2020) Lunit releases its aI online to support healthcare professionals manage COVID-19. https://www.lunit.io/en/ news/lunit-releases-its-ai-online-to-support-healthcare-profe ssionals-manage-covid-19. Accessed 12 Apr 2021

80. Reuters (2020) Israeli defense ministry launches COVID-19 voice-test study. https://www.reuters.com/article/us-healthcoronavirus-israel-study-idUSKBN21B2YV. Accessed 14 Apr 2021

81. Wiggers K (2020) Cordio and rambam hospital will trial AI that detects coronavirus cases from speech samples. https:// venturebeat.com/2020/04/01/cordio-and-rambam-hospitalwill-trial-ai-that-detects-coronavirus-cases-from-speech-sampl es/. Accessed 15 Apr 2021

82. Lovell T. Two Israeli hospitals launch AI-based tele-ICU to support COVID-19 patients. Healthcare IT News, 2020. https:// www.healthcareitnews.com/news/emea/two-israeli-hospitalslaunch-ai-based-tele-icu-support-covid-19-patients. Accessed 23 Aug 2020.

83. Heaven WD israel is using AI to flag high-risk covid-19 patients. In: MIT Technol. Rev. https://www.technologyreview. 
com/2020/04/24/1000543/israel-ai-prediction-medical-testingdata-high-risk-covid-19-patients/. Accessed 15 Apr 2021

84. Pennic F (2020) Israel aerospace develops aI-based model to predict progression of COVID-19 patients. In: HIT Consult. https://hitconsultant.net/2020/06/08/israel-aerospace-developsai-based-model-to-predict-progression-of-covid-19/. Accessed 16 Apr 2021

85. Karp P. Government increases spend on Covid-19 data analytics as it declines to release modelling. The Guardian. 2020. https://www.theguardian.com/australia-news/2020/mar/28/ government-increases-spend-on-covid-19-data-analytics-asit-declines-to-release-modelling. Accessed 27 Jul 2020.

86. Singer S. How big data is powering Australia's COVID-19 response. Government News. 2020. https://www.government news.com.au/type_contributors/how-big-data-is-poweringaustralias-covid-19-response/. Accessed 27 Jul 2020.

87. Huber N. Tech consultants join Gulf's fight against Covid-19. Financial Times, 2020. https://www.ft.com/content/ae6bb8527a74-11ea-bd25-7fd923850377. Accessed 13 Jul 2020.

88. Graham E (2020) Some countries in the middle east are using artificial intelligence to fight the coronavirus pandemic. In: CNBC. https://www.cnbc.com/2020/04/16/countries-in-the-middle-east-are-using-ai-to-fight-coronavirus.html. Accessed $18 \mathrm{Apr}$ 2021

89. EPC (2020) How did the UAE employ artificial intelligence to limit the spread of COVID-19? https://epc.ae/brief/how-did-theuae-employ-artificial-intelligence-to-limit-the-spread-of-covid19. Accessed 18 Apr 2021

90. G42 (2020) G42 and BGI Announce COVID-19 Detection Lab. https://www.bgi.com/global/company/news/g42-and-bgi-annou nce-covid-19-detection-lab/. Accessed 19 Apr 2021

91. G42 (2020) G42 Healthcare Launches Health AI Services to Accelerate COVID-19 Diagnosis and Drug Discovery. https:// g42.ai/news/healthcare/health-ai-platform/. Accessed $20 \mathrm{Apr}$ 2021

92. ETGovernment (2020) Centre's 'Aarogya Setu' app to track Covid-19 infected cases. https://government.economictimes.india times.com/news/digital-india/centres-aarogya-setu-app-to-trackcovid-19-infected-cases/74962044. Accessed 21 Aug 2020

93. Thomas A (2020) How different states in india are sing aIpowered tools to combat Covid-19. In: Anal. india Mag. https:// analyticsindiamag.com/how-states-in-india-are-using-ai-power ed-tools-to-combat-covid-19/. Accessed 25 Aug 2020

94. Prasad R (2020) L\&T uses artificial intelligence to help 20 cities combat Covid-19. In: Econ. Times. https://economictimes.india times.com/tech/ites/lt-uses-artificial-intelligence-to-help-20-cities-combat-covid-19/articleshow/75073867.cms. Accessed 28 Aug 2020

95. Dutta A, Haq Z (2020) In the back-end of the Covid-19 fight, big data works silently. In: Hindustan Times. https://www.hindu stantimes.com/india-news/in-the-back-end-of-the-covid-fightbig-data-works-silently/story-PzzI8szh3T5ztIMW9JoDoJ.html. Accessed 30 Aug 2020

96. Jaiswal PB (2020) How Artificial intelligence-backed technology is helping in the battle against COVID-19. In: Week. https:// www.theweek.in/news/sci-tech/2020/06/08/how-artificial-intel ligence-backed-technology-is-helping-in-the-battle-againstcovid-19.html. Accessed 27 Sep 2021

97. Behold.ai. Behold.ai partners with Apollo Hospitals Group, India for rapid COVID-19 diagnosis using AI-based chest X-ray technology. 2020. https://behold.ai/behold-ai-partners-with-apollohospitals-group-india-for-rapid-covid-19-diagnosis-using-aibased-chest-x-ray-technology/. Accessed 29 Jul 2020.

98. PTI (2020) Pune institute develops aI for detection of COVID-19. https://www.businessinsider.in/india/news/pune-institute-devel ops-ai-for-detection-of-covid-19/articleshow/76156304.cms. Accessed 2 Sep 2020

99. The hindu business line (2020) IIT-hyderabad develops aI-based Covid-19 test kit priced at ₹600. https://www.thehindubusines sline.com/news/science/iit-h-develops-ai-based-covid-19-testkit-priced-at-600/article31773056.ece. Accessed 6 Sep 2020

100. DST (2020) DST initiates COVID-19 India national supermodel for monitoring infection transmission \& aid decision-making by policymakers. https://dst.gov.in/dst-initiates-covid-19-india-natio nal-supermodel-monitoring-infection-transmission-aid-decision. Accessed 8 Sep 2020

101. Bogoch II, Watts A, Thomas-bachli A, Msa CH, Dphil MUGK, Khan K. Potential for global spread of a novel coronavirus from China. pp. 1-3, 2020.

102. Bogoch II, Watts A, Thomas-bachli A, Huber C, Kraemer MUG, Khan K. Pneumonia of unknown aetiology in Wuhan, China: potential for international spread via commercial air travel. pp. $1-3,2020$.

103. Huang $L$ et al. LinearFold: linear-time approximate RNA folding by 5' -to-3' dynamic programming and beam search. 2019.

104. Baidu. How Baidu is bringing AI to the fight against coronavirus. MIT Technology Review. 2020. https://www.technologyreview. com/2020/03/11/905366/how-baidu-is-bringing-ai-to-the-fightagainst-coronavirus/. Accessed 20 Sep 2021.

105. Liang V. Baidu's AI-related patented technologies: Doing battle with COVID-19. Wipo Magazine. 2020. https://www.wipo.int/ wipo_magazine/en/2020/02/article_0003.html. Accessed 20 Sep 2021.

106. Pham QV, Nguyen DC, Huynh-The T, Hwang WJ, Pathirana PN. Artificial Intelligence (AI) and big data for coronavirus (COVID19) pandemic: a survey on the state-of-the-Arts. IEEE Access. 2020;8(Cdc):130820-39.

107. Knowles C. Alibaba Cloud connects medical pros around the world during COVID-19. IT Brief Asia. 2020. https://itbrief.asia/ story/alibaba-cloud-connects-medical-pros-around-the-worldduring-covid-19. Accessed 20 Sep 2021.

108. Yu E. Alibaba Cloud offers AI platform to support coronavirus medical efforts. ZDNet, 2020. https://www.zdnet.com/article/ alibaba-cloud-offers-ai-platform-to-support-coronavirus-medic al-research/. Accessed 20 Sep 2021.

109. Boulos MNK, Geraghty EM. Geographical tracking and mapping of coronavirus disease COVID-19/severe acute respiratory syndrome coronavirus 2 (SARS-CoV-2) epidemic and associated events around the world: how 21st century GIS technologies are supporting the global fight ag. Int J Health Geogr. 2020;19:1-12.

110. National Health Commission of the People's Republic of China. China introduces novel coronavirus close contact detection app. 2020. http://en.nhc.gov.cn/2020-02/10/c_76416.htm. Accessed 20 Sep 2021.

111. CHINA UNICOM (HONG KONG) LIMITED (2020) Pandemic control. https://www.chinaunicom.com.hk/en/csr/csr2020/csr20 20_04.pdf. Accessed 21 Aug 2021

112. Tuli S, Tuli S, Tuli R, Gill SS. Predicting the growth and trend of COVID-19 pandemic using machine learning and cloud computing. Internet of Things. 2020;11:100222.

113. Ministry of Foreign Affairs the People's Republic of China. To Promote Building Community of Health by Fighting Epidemic. 2020. https://www.fmprc.gov.cn/mfa_eng/wjb_663304/zwjg_ 665342/zwbd_665378/t1771375.shtml. Accessed 20 Sep 2021.

114. Menni C, et al. Real-time tracking of self-reported symptoms to predict potential COVID-19. Nat Med. 2020;26(7):1037-40.

115. Antonelli $\mathrm{M}$ et al. Risk factors and disease profile of postvaccination SARS-CoV-2 infection in UK users of the COVID Symptom Study app: a prospective, community-based, nested, case-control study. Lancet Infect Dis. 2021; 1-13. 
116. Drew DA, et al. Rapid implementation of mobile technology for real-time epidemiology of COVID-19. Science (80-). 2020;368(6497):1362-7.

117. Wright JV. behold.ai's red $\operatorname{dot}{ }^{\circledR}$ AI algorithm identifies chest X-rays from COVID-19 patients as 'abnormal,"' behold.ai. 2020. https://behold.ai/behold-ais-red-dot-ai-algorithm-identifieschest-x-rays-from-covid-19-patients-as-abnormal/. Accessed 21 Sep 2021.

118. Spinner J. AI Vivo: dexamethasone shows promise as COVID-19 treatment. Outsourcing Pharma. 2020. https://www.outsourcingpharma.com/Article/2020/06/25/Dexamethasone-shows-promi se-as-COVID-19-treatment. Accessed 21 Sep 2021.

119. Kang R. Baricitinib, first identified by BenevolentAI as a COVID-19 treatment, is granted emergency use in India in response to its escalating crisis. Benevolent. 2021. https://www. benevolent.com/news/baricitinib-first-identified-by-benevolent ai-as-a-covid-19-treatment-is-granted-emergency-use-in-indiain-response-to-its-escalating-crisis\%0A. Accessed 21 Sep 2021.

120. Benevolent. Potential treatment for COVID-19 identified by BenevolentAI enters randomised clinical trial. Benevolent. 2020. https://www.benevolent.com/news/potential-treatment-for-covid19-identified-by-benevolentai-using-artificial-intelligence-entersrandomised-clinical-trial. Accessed 21 Sep 2021.

121. Diamond Light Source. Joint initiative announced to accelerate the search for COVID-19 drugs. Diamond Light Source. 2020. https://www.diamond.ac.uk/Home/News/LatestNews/2020/3103-2020.html. Accessed 21 Sep 2021.

122. McKenna B. Coronavirus: NHS corrals Microsoft, Palantir and Google to hone data analysis. Computer Weekly. 2020. https:// www.computerweekly.com/news/252480796/Coronavirus-NHScorrals-Microsoft-Palantir-and-Google-to-hone-data-analysis. Accessed 21 Sep 2021.

123. Gould M, Joshi DI, Tang M. The power of data in a pandemic. Gov.UK. 2020. https://healthtech.blog.gov.uk/2020/03/28/thepower-of-data-in-a-pandemic/. Accessed 21 Sep 2021.

124. tellic. Online tool to accelerate COVID-19 research. Telic. 2020. https://info.tellic.com/tellic-graph.covid-19-registration. Accessed 22 Sep 2021.

125. tellic. tellic gives scientists free access to AI tool that accelerates COVID-19 research. News Wise. 2020. https://www.newsw ise.com/coronavirus/tellic-gives-scientists-free-access-to-aitool-that-accelerates-covid-19-research/?article_id=729131. Accessed 22 Sep 2021.

126. Adaptive Biotechnologies. Adaptive Biotechnologies Launches immunoSEQ T-MAP COVID, First Molecular T Cell Monitoring Tool for SARS-CoV-2. Adaptive Biotechnologies. 2020. https:// investors.adaptivebiotech.com/news-releases/news-release-detai 1s/adaptive-biotechnologies-launches-immunoseq-t-map-covidfirst. Accessed 22 Sep 2021.

127. Nolan $\mathrm{S}$ et al. A large-scale database of T-cell receptor beta (TCR $\beta$ ) sequences and binding associations from natural and synthetic exposure to SARS-CoV-2. pp. 1-28.

128. Senior AW, et al. Improved protein structure prediction using potentials from deep learning. Nature. 2020;577(7792):706-10.

129. Wang LL, Lo K, Chandrasekhar Y, et al (2020) CORD-19 The COVID-19 Open Research Dataset. arXiv

130. Kent J. White House Urges AI Experts to Develop Tools for COVID-19 Dataset. Health IT Analytics. 2020. https://healthitan alytics.com/news/white-house-urges-ai-experts-to-develop-toolsfor-covid-19-dataset. Accessed 22 Sep 2021.

131. Siwicki B. Remote patient monitoring helps Baptist Health achieve zero readmissions with COVID-19 patients. Healthcare IT News. 2021. https://www.healthcareitnews.com/news/remotepatient-monitoring-helps-baptist-health-achieve-zero-readmissio ns-covid-19-patients. Accessed 22 Sep 2021.
132. Devaraj J, et al. Forecasting of COVID-19 cases using deep learning models: is it reliable and practically significant? Results Phys. 2021;21(October 2020):103817.

133. Kahan J. Mobilizing AI for Health to fight against COVID-19. Microsoft. 2020. https://blogs.microsoft.com/on-the-issues/2020/ 04/09/ai-for-health-covid-19/. Accessed 22 Sep 2021.

134. University of Washington. University of Washington COVID-19 Case Tracking Dashboard. 2020. https://www.washington.edu/ coronavirus/testing-results/. Accessed 22 Sep 2021.

135. expert.ai. AI to support Covid-19 Research. expert.ai. 2020. https://www.expert.ai/case-studies/the-french-national-instituteof-health-and-medical-research-inserm-selects-expert-systemsartificial-intelligence-to-support-covid-19-research/. Accessed 23 Sep 2021.

136. DZD. Coronavirus SARS-COV-2: Research Activities of the DZD. DZD. 2020. https://www.dzd-ev.de/en/latest/news/news/ article/coronavirus-sars-cov-2-research-activities-of-the-dzd/ index.html. Accessed 24 Sep 2021.

137. Jarasch A. Using graphs to develop a deeper understanding of COVID-19. Healthcare IT News. 2020. https://www.healthcare itnews.com/blog/emea/using-graphs-develop-deeper-understand ing-covid-19. Accessed 24 Sep 2021.

138. Stefan N, Birkenfeld AL, Schulze MB, Ludwig DS. Obesity and impaired metabolic health in patients with COVID-19. Nat Rev Endocrinol. 2020;16(7):341-2.

139. Here Technologies. Enel $X$ and HERE Technologies launch 'City Analytics-Mobility Map' to support government agencies and the Civil Protection department in response to the COVID-19 emergency. Enel. 2020. https://www.enel.com/media/explore/ search-press-releases/press/2020/04/enel-x-and-here-technologi es-launch-city-analytics--mobility-map-to-support-governmentagencies-and-the-civil-protection-department-in-response-to-thecovid-19-emergency. Accessed 23 Sep 2021.

140. Lunit. Lunit INSIGHT CXR. Lunit. 2020. https://www.lunit.io/ en/products/insight-cxr. Accessed 24 Sep 2021.

141. Borowiec S. AI and X-rays: Identifying the many faces of COVID-19. Microsoft. 2021. https://news.microsoft.com/apac/ features/ai-and-x-rays-identifying-the-many-faces-of-covid-19/. Accessed 24 Sep 2021.

142. ITU News. COVID-19: How Korea is using innovative technology and AI to flatten the curve. ITU News. 2020. https://news. itu.int/covid-19-how-korea-is-using-innovative-technology-andai-to-flatten-the-curve/. Accessed 24 Sep 2021.

143. Watson I, Jeong S, Hollingsworth J, Tom. How this South Korean company created coronavirus test kits in three weeks. CNN. 2020. https://edition.cnn.com/2020/03/12/asia/coronavirussouth-korea-testing-intl-hnk/index.html. Accessed 24 Sep 2021.

144. Schwartz EH. Israeli Startup Vocalis Health is Partnering with the Government to Refine a Voice Test for Coronavirus. voicebot.ai. 2020. https://voicebot.ai/2020/04/15/israeli-start up-vocalis-health-is-partnering-with-the-government-to-refinea-voice-test-for-coronavirus/. Accessed 24 Sep 2021.

145. Child J, Dillon R, Erasmus E, Johnson J. Collaboration in crisis: Reflecting on Australia's COVID-19 response. McKinsey \& Company. 2020. https://www.mckinsey.com/industries/public-and-social-sector/our-insights/collaboration-in-crisis-refle cting-on-australias-covid-19-response\%0A. Accessed 25 Sep 2021.

146. Tynes N. Arab healthcare innovation responds to pandemic. Nat Middle East. 2020. https://doi.org/10.1038/nmiddleeast. 2020.62.

147. McArthur R. UAE and UK partnership unveils scalable solution for COVID-19 detection. Mobile Health News. 2020. https:// www.mobihealthnews.com/news/emea/uae-and-uk-partnershipunveils-scalable-solution-covid-19-detection. Accessed 27 Sep 2021. 
148. SEHA. Combating coronavirus: Abu Dhabi uses artificial intelligence to predict, prevent Covid-19 spread. SEHA-Abu Dhabi Health Services Company. 2020. https://www.seha.ae/comba ting-coronavirus-abu-dhabi-uses-artificial-intelligence-to-predi ct-prevent-covid-19-spread/. Accessed 26 Sep 2021.

149. Malek C. A Saudi-based startup seeks to expand availability of AI solutions. Arab News. 2021. https://www.arabnews.com/ node/1898046/business-economy. Accessed 26 Sep 2021.

150. Coviself. Mylab receives ICMR approval for India's First SelfUse Covid-19 Test. Mylab Discovery Solutions. 2020. https:// coviself.com/img/CoviSelf-Press-Release.pdf. Accessed 27 Sep 2021.

151. Hospital Management (2020) Apollo Hospitals partners Behold. ai for X-ray technology. In: Hosp. Manage. https://www.hospi talmanagement.net/digital-disruptions/ai/apollo-hospitalsbehold-ai/. Accessed 27 Sep 2021

152. Larsen \& Toubro. Technology to fight COVID19. Larsen \& Toubro. 2020. https://www.larsentoubro.com/corporate/aboutlt-group/technology-for-growth/technology-to-fight-covid19/. Accessed 27 Sep 2021.

153. INDIAai. AI solutions from L\&T to help 20 cities in India to combat COVID-19. INDIAai. 2020. https://indiaai.gov.in/news/ ai-solutions-from-1-t-to-help-20-cities-in-india-to-combat-covid19. Accessed 27 Sep 2021.

154. Gupta R, Bedi M, Goyal P, Wadhera S, Verma V. Analysis of COVID-19 tracking tool in India: case study of Aarogya Setu mobile application. Digit Gov Res Pract. 2020;1(4):28:1-28:8.

155. Ahuja V, Nair LV. Artificial Intelligence and technology in COVID Era: a narrative review. J Anaesthesiol Clin Pharmacol. 2021;37(1):26-34.

156. Aarogya Setu. How Aarogyasetu Knows about your COVID-19 positive status?. Aarogya Setu. 2020. https://www.aarogyasetu. gov.in/. Accessed 26 Sep 2021.

157. Path (2020) India fights COVID-19. https://www.indiasanitation coalition.org/uploaded_files/partner_action_cat/1590217915_ 776.pdf. Accessed 27 Sep 2021

158. Jayadas N, Suresh R, Rajan R. Smarter City: how AI is enabling Mumbai battle COVID-19. Qure.ai. 2020. https://blog.qure.ai/ notes/smart-city-ai-enabling-mumbai-battle-covid19. Accessed 27 Sep 2021.

159. Jaiswal PB. How Artificial Intelligence-backed technology is helping in the battle against COVID-19. The Week. 2020. https:// www.theweek.in/news/sci-tech/2020/06/08/how-artificial-intel ligence-backed-technology-is-helping-in-the-battle-againstcovid-19.html. Accessed 27 Sep 2021.

160. Wiersinga WJ, Rhodes A, Cheng AC, Peacock SJ, Prescott HC. Pathophysiology, transmission, diagnosis, and treatment of coronavirus disease 2019 (COVID-19): a review. JAMA J Am Med Assoc. 2020;324(8):782-93.

161. Sanaie S, Golipour E, Shamekh A, Sadaie MR, Mahmoodpoor A, Yousefi M. Immune response variables and viral mutations impact on COVID-19 reinfection and relapse. Int Immunopharmacol. 2021;100(January):108108.

162. Cascella M, Rajnik M, Aleem A, Dulebohn SC, Di Napoli R. Features, Evaluation, and Treatment of Coronavirus (COVID19), Jan. Treasure Island: StatPearls Publishing; 2021.

163. Badker R, et al. Challenges in reported COVID-19 data: best practices and recommendations for future epidemics. BMJ Glob Heal. 2021;6(5):e005542.
164. Naudé W (2020) Artificial Intelligence against COVID-19: An early revie. https://www.iza.org/publications/dp/13110/artificialintelligence-against-covid-19-an-early-review. Accessed 22 Sep 2021

165. Kendale SM, Jabaley CS, Long DR. The COVID-19 pandemic highlights shortcomings in US health care informatics infrastructure: a call to action. Anesth Analgesia. 2020;1-5.

166. Zeidan B. COVID-19 Highlights the Need for Interoperability in Healthcare. Bio IT World. 2021. https://www.bio-itworld.com/ news/2021/04/16/covid-19-highlights-the-need-for-interopera bility-in-healthcare. Accessed 27 Sep 2021.

167. Sridhara S. Challenges to data access and interoperability. Optum. 2020. https://www.optum.com/business/resources/ health-care-tech-blog/pandemic-perspectives-interoperability. html. Accessed 27 Sep 2021.

168. Fegan G, Cheah PY, Sharing D, Group W. Solutions to COVID19 data sharing. Lancet Digit Heal. 2021;3(1):e6.

169. F. Gao, L. Tao, Y. Huang, and S. Zhiquan. Management and Data Sharing of COVID-19 Pandemic Information. Biopreserv. Biobank., vol. 18, no. 6, 2020.

170. Ashofteh A, Bravo JM. A study on the quality of novel coronavirus (COVID-19) official datasets. no. June 2020, 2021.

171. Woodie A. Coming to Grips with COVID-19's Data Quality Challenges. Datanami. 2020. https://www.datanami.com/2020/ 04/21/coming-to-grips-with-covid-19s-data-quality-challenges/. Accessed 27 Sep 2021.

172. Kundu S, Elhalawani H, Gichoya JW, Kahn CE. How might AI and chest imaging help unravel COVID-19's mysteries? Radiol Artif Intell. 2020;2(3):e200053.

173. Mikkelsen D, Soller H, Strandell-Jansson M. Privacy, security, and public health in a pandemic year. McKinsey \& Company. 2020. https://www.mckinsey.com/business-functions/risk-andresilience/our-insights/privacy-security-and-public-health-in-apandemic-year. Accessed 28 Sep 2021.

174. Belkhelladi A, Dewitt B, Frank D, Sponselee A (2020) COVID19: privacy and security in the next normal. https://www2.deloi tte.com/global/en/pages/about-deloitte/articles/covid-19/priva cy-and-security-in-the-next-normal.html. Accessed 28 Sep 2021

175. Zwitter A, Gstrein OJ (2020) Big data, privacy and COVID19 - learning from humanitarian expertise in data protection. J Int Humanit Action 5:4. https://doi.org/10.1186/ s41018-020-00072-6

176. Hewage C, Forné J, Shaikh R, Cabarcos PA. Special Issue 'Privacy and Security Landscape and Challenges beyond COVID19'. MDPI. 2021. https://www.mdpi.com/journal/futureinternet/ special_issues/PSLC_COVID19. Accessed 28 Sep 2021.

177. Zaboeva C, Frydrych M. IBM uncovers global phishing campaign targeting the COVID-19 vaccine cold chain. Security Intelligence, IBM. 2020. https://securityintelligence.com/posts/ ibm-uncovers-global-phishing-covid-19-vaccine-cold-chain/. Accessed 28 Sep 2021.

Publisher's Note Springer Nature remains neutral with regard to jurisdictional claims in published maps and institutional affiliations. 